\title{
Decoding the Role of Serum IL-12 as a Prognostic Biomarker in Pegylated IFN-a-2a / Ribavirin- Treated Chronic Hepatitis C Patients using Luminex xMAP Technology
}

\author{
M. Haroon Hamed ${ }^{1}$, Peter Natesan Pushparaj ${ }^{2}$, Salem Bazarah ${ }^{3}$, Saleh Karim ${ }^{1}$, Khalid Alghamdy ${ }^{1}$ and Ishtiaq \\ Qadri' ${ }^{1 *}$ \\ ${ }^{1}$ Department of Biological Sciences, King Abdulaziz University, Saudi Arabia
}

2Center of Excellence in Genomic Medicine Research, Faculty of Applied Medical Sciences, King Abdulaziz University, Saudi Arabia

${ }^{3}$ College of medicine, King Abdulaziz University hospital, Saudi Arabia

Submission: January 01, 2017; Published: January 12, 2017

"Corresponding author: Ishtiaq Qadri, Department of Biological Sciences, King Abdulaziz University, Jeddah, Saudi Arabia, Tel: 00966535168434; Email: ishtiaq80262@yahoo.com

\begin{abstract}
Hepatitis C Virus (HCV) infects 3\% of the world population. It leads to liver morbidity and transplantation. Various liver function tests are used to monitor the disease progression but they are not robust. Immune system of the host triggers when HCV invades the body. Proinflammatory cytokines like IL-12 may be a novel biomarker for the therapy outcome and for the progression of hepatocellular carcinoma. In this study, we have examined the role of IL-12 in HCV genotype 4 patients with interferon resistance and strong correlation was observed with the resistance.
\end{abstract}

Keywords: IL-12, ALT, AST, HCV, Cytokines.

\section{Introduction}

Hepatitis C virus (HCV) infection accounts for almost 3\% of the world's population [1]. Almost $70 \%$ infected patients get chronic hepatitis while around 30\% express complete recovery [2]. The pathogenicity of viral infections are highly predisposed by the host immune response. Immune system of the body eradicate several viruses at their acute stage, though HBV (hepatitis B virus) and HCV (hepatitis C virus) can evade the host immune system and develop persistent infection [3]. Interleukin 12 (IL-12) is a 70-kilo Dalton hetero-dimer protein, comprised of p40 and p35 subunits.These subunits are encoded by two separate genes present on two different chromosomes [4]. IL-12 performs its role as a linkage among the innate and the adaptive immune reactions and as a hazardous part in immune pathogenesis of various diseases [5]. IL-12 expresses antiviral role as an activator of natural killer cells, inducer of interferon $\gamma$, and cytotoxic lymphocytes. These all factors are vital part of anti-HCV immune responses [6]. IFN- stimulation results the production of antigen which causes the creation of pro- inflammatory cytokine IL-12 [7]. Therefore IL-12 is considered as a distinct Th1 and Th2 differentiation determining factor [8]. This study was intended to explore the expression of IL-12 in interferon responders and non-responders of hepatitis $\mathrm{C}$ infection and to assess their possible role as new biomarker for the treatment response.

\section{Materials and Methods}

Subjects

Ethical approval was obtained from ethical committee of King Abdul Aziz university Jeddah and patients were recruited with their informed consent. The medical history of the patients was obtained (viral load) and different biochemical changes (AST, ALT AFT) were observed in their blood before and after the interferon treatment. All data is shown in results Table 1.

A total of 20 patients with HCV infection and 10 healthy controls were enrolled in this study. All patients were hospitalized or were present for followed-up examinations in the King Abdul 
Aziz University Hospital Jeddah KSA. Diagnoses were made in accordance with the standard procedure of the hospital for the prevention and treatment of viral hepatitis. Ten (10) healthy individuals who matched for sex ratio and mean age were also enrolled for normal controls (NC). No subjects were co-infected with HIV or other hepatitis viruses. Eighteen patients with HCV infection received peg-interferon and ribavirin treatment for 48 weeks, out of nine patients showed resistance to the treatment. Blood samples were collected at start and end of the treatment. Based on the therapeutic response to antiviral treatment, those 18 patients were divide into two groups: Responder (R), nonresponder (NR) and each group had nine patients.

Criteria of responder and non-responder was as following

i. Responders (R) when HCV RNA in patient's sera was undetectable at 48 weeks at end of the treatment. (Also known as SVR i.e. sustained virological response)

ii. Non-responders (NR) when HCV RNA in patient's sera was detectable at the end of therapy.

\section{Whole blood samples}

Blood was collected from recruited patients. Serum samples were collected by centrifugation of blood at 3,000 g for $10 \mathrm{~min}$, and stored immediately to $-80^{\circ} \mathrm{C}$ until use.

\section{Viral load}

Plasma HCV RNA levels were measured by using of the COBAS TaqMan HCV test, version 2.0 (Roche), with a lower limit of detection of $50 \mathrm{IU} / \mathrm{ml}$ (Table 1 ).

Table 1: Clinical and virological parameters assessed in this study:.

\begin{tabular}{|c|c|c|}
\hline Demographic/Clinical parameter (Mean \pm SE) & NR & $\mathbf{R}$ \\
\hline Age (years) & $57 \pm 2.350$ & $62.6 \pm 6.266$ \\
\hline BMI $\left(\mathrm{kg} / \mathrm{m}^{2}\right)$ & $31.08 \pm 1.415$ & $24.16 \pm 1.802$ \\
\hline LFT/AST before Treatment (U/L) & $49.57 \pm 9.040$ & $57.6 \pm 16.042$ \\
\hline LFT/AST After Treatment (U/L) & $72.43 \pm 13.508$ & $40.3 \pm 14.448$ \\
\hline LFT/ALT before Treatment (U/L) & $53.5 \pm 10.844$ & $65.1 \pm 22.727$ \\
\hline LFT/ALT After Treatment (U/L) & $58.14 \pm 14.805$ & $29 \pm 7.0193$ \\
\hline Viral load Before treatment(IU/ML (Mean) & 3172545 & 352533.2 \\
\hline Viral load after treatment IU/ML (Mean) & 4098385 & 49 \\
\hline
\end{tabular}

(NR= Non-responders, $\mathrm{R}=$ Responders, LFT/ALT/AST= Liver function tests)

\section{Chemokines assay $(\mathrm{pg} / \mathrm{mL})$ and bead preparation}

Preparation of beads was done according to the manufacture`s guidelines by using Novex (Life Technologies), Human Cytokine Magnetic 30-plex panel, the sera from interferon responders vs. non responders were compared. This system is very robust and quantitative differences can be measured easily. These results indicate a significant increase of IL-12 in non-responder patients (Figure 1).

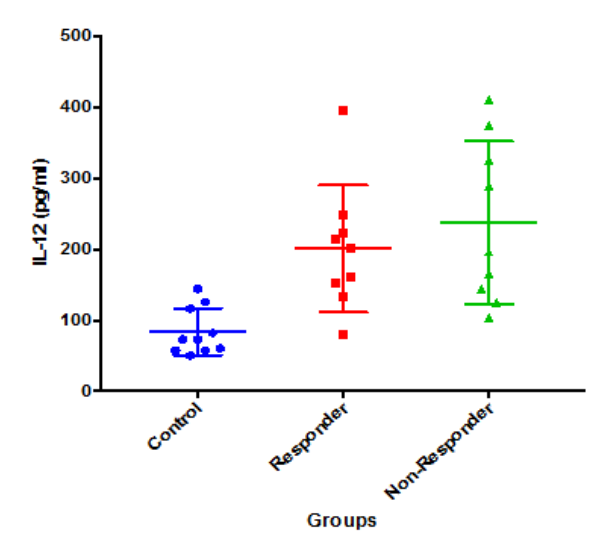

Figure 1. Serum IL-12 concentration estimated by MAGPIX. The expression of IL-12 was significantly different from $R$ and control groups.

\section{Statistical analyses}

Data were analyzed using MINITAB version 17 and figure was constructed using GraphPad Prism version 7. P values of less than or equal to 0.05 were used as a benchmark to assess the statistical significance.

\section{Results}

Biochemical responses in responder and non-responders:

It is clearly stated that biochemical parameters like LFT, AST and ALT are correlated with therapy outcome.The values of these parameters are decreased in responders while increased in nonresponders representing that hepatitis $\mathrm{C}$ virus played a vital role to make changes in non-responders. The values of viral load show the same trend between NR and R, details are in Table 1.

\section{Discussion}

Cytokines play a vital role in viral clearance, control of infection, swelling, restoration, fibrosis and are concerned in the irrational procedures arising in the liver throughout viral infection [9]. Therefore, our study was aimed to explore serum level of IL-12 in prolonged liver disease and their association with HCV infection (non-responders to the therapy) This study appraised IL-12 as a new biomarker in chronic inflammatory progression leading to Hepatocellular carcinoma. IL-12 is one 
of the most important pro-inflammatory cytokines presented with the initiation of immune response, determining Th1 and Th2 differentiation [1]. Serum level of different chemokines, growth factors and cytokines were analyzed by capone et al. [10], in this study the findings showed the higher level of mean concentrations in interferon resistance and hepatocellular carcinoma patients compared to the normal. Our results are consistent with those findings where serum levels of IL-12 were more elevated in interferon non-responders $(\mathrm{P}<0.0001)$ patients as compared to responders $(\mathrm{P}<0.001)$. In summary, these findings explore that IL-12, pro-inflammatory molecules, tend to rise in chronic HCV [9]. Another study also supports our findings in which IL-12 is significantly elevated in HCV infected patients compared to healthy control group $[11,12]$. Our study of HCV genotype 4 is unique as no comparison was found from the literature where responder and non- responders are compared. We concluded that these strong pro-inflammatory responses might play a vital role to develop hepatic injury which could be used as immunological biomarker to the pathogenicity of liver manifestation [13].

\section{Conclusion}

The significantly elevated levels of ALT, AST and IL-12 in HCV genotype 4 non-responders to the therapy indicate that these factors may influence the disease progression resulting hepatocellular carcinoma and IL-12 might be considered as a novel biomarker for hepatic carcinoma.

\section{Acknowledgment}

Financial support was provided by king Abdulaziz City for Science and technology (KACST) large grant 162-34, to Ishtiaq Qadri.

\section{References}

1. SS Youssef, AM Abd El-Aal, A Saad, MH Omran, T El Zanaty, at al (2013) Impact of IL12B gene rs 3212227 polymorphism on fibrosis, liver inflammation, and response to treatment in genotype 4 Egyptian hepatitis c patients. Disease Markers 35(5): 431-437.
2. MH Omran, NE Ibrahim, SS Youssef, et al. (2013) Relation of interleukin-1 gene to treatment response in chronic patients infected with HCV genotype 4. Journal of Infection in Developing Countries 7(11): 851-858.

3. E Billerbeck, TB ottler, R Thimme (2007) Regulatory T cells in viral hepatitis. World Journal of Gastroenterology 13(36): 4858-4864.

4. Miguel, A Xiaojing, M Alexandrina, SGiorgio T (1998) Molecular mechanisms of the induction of il-12 and its inhi- bition by il-10. J Immunol 160(12): 5936-5944.

5. Marshall JD, Chehimi J, Gri G, Kostman JR, Montaner LJ, et al. (1999) The interleukin-12-mediated pathway of immune events is dysfunctional in human immunodeficiency virus-infected individuals. Blood 94(3): $1003-1011$.

6. Poynard T, Ngo Y, Munteanu M, Thabut D, Massard J, Moussalli J, et al. (2010) Biomarkers of liver injury for hepatitis clinical trials: a metaanalysis of longitudinal studies. Antiviral Ther 15(4): 617-631.

7. Del Vecchio M, Bajetta E, Canova S, Lotze MT, Wesa A, et al. (2007) Interleukin-12: biological properties and clinical application. Clin Cancer Res 13(16): 4677-4685.

8. Watford WT, Moriguchi M, Morinobu A, O'Shea JJ (2003) The biology of IL-12: coordinating innate and adaptive immune responses. Cytokine Growth Factor Rev 14(5): 361-368.

9. Costantini S, Capone F, Guerriero E, Maio P, Colonna G (2010) Serum cytokine levels as putative prognostic markers in the progression of chronic HCV hepatitis to cirrhosis. Eur Cytokine Netw 21(4): 251-256.

10. Capone F, Costantini S, Guerriero E, Calemma R, Napolitano M, et al. (2010) Serum cytokine levels in patients with hepatocellular carcinoma. Eur Cytokine Netw 21(2): 99-104.

11. Kakumu S, Okumura A, Ishikawa T, Iwata K, Yano M, et al. (1997) Production of interleukins 10 and 12 by peripheral blood mononuclear cells (PBMC) in chronic hepatitis C virus (HCV) infection. Clin Exp Immunol 108(1): 138-143.

12. Sarih M, Bouchrit N, Benslimane A (2000) Different cytokine profiles of peripheral blood mononuclear cells from patients with persistent and self-limited hepatitis C virus infection. Immunol Lett 74( 2): 117-120.

13. Gigi E, Raptopoulou-Gigi M, Kalogeridis A, Masiou S, Orphanou E et al. (2008) Cytokine mRNA expression in hepatitis $C$ virus infection: $\mathrm{TH} 1$ predominance in patients with chronic hepatitis $\mathrm{C}$ and TH1-TH2 cytokine profile in subjects with self-limited disease. J Viral Hepat 15(2): 145-154.

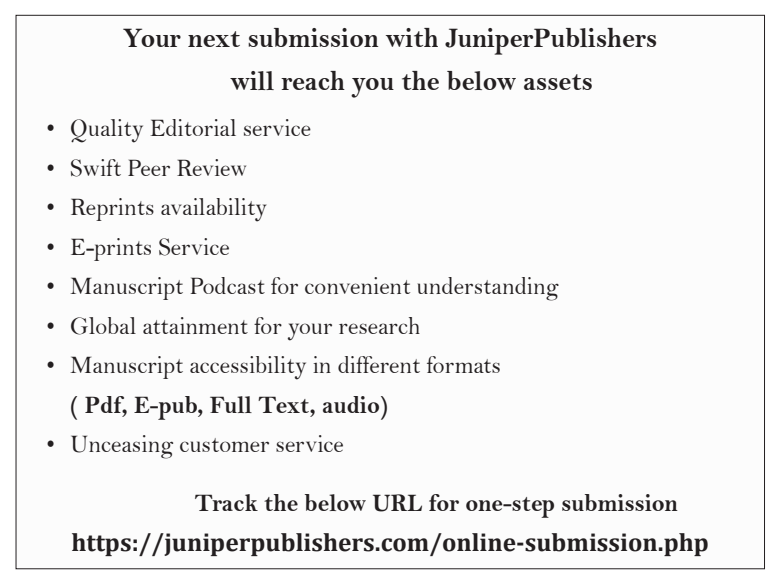

